Kalpachev, S.N. (2021). Challenges in determining the contribution of the operating system to the formation of competitive advantages of the enterprise. Management as a science of complex development. Collection of Scientific Articles, European Scientific e-Journal, 6 (12), 19-32. Hlučín-Bobrovníky: “Anisiia Tomanek" OSVČ. (in Bulgarian)

Калпачев, С.Н. (2021). Предизвикателства при детерминирането на приноса на операционната система за формирането на конкурентни предимства на предприятието. Management as a science of complex development. Collection of Scientific Articles, European Scientific e-Journal, 6 (12), 19-32. Hlučín-Bobrovníky: "Anisiia Tomanek" OSVČ.

DOI: $10.47451 / \operatorname{man} 2021-04-001$

EOI: $10.11244 / \operatorname{man} 2021-04-001$

The paper is published in Crossref, Internet Archive, Google Scholar, Academic Resource Index ResearchBib, JGate, ISI, CiteFactor, ICI, eLibrary databases.

Stefan Nankov Kalpachev

Chief assistant professor, Doctor of Science Department of Industrial Business and Logistics

Faculty of Economics

University of Economics - Varna

Varna, Bulgaria

E-mail: stefan.kalpachev@ue-varna.bg

\title{
Challenges in determining the contribution of the operating system to the formation of competitive advantages of the enterprise (in Bulgarian)
}

Abstract:

The purpose of this article is to outline the challenges in determining the contribution of the operating system to the formation of competitive advantages of the enterprise based on the application of resource-based theory. Due to the growing number of publications linking the resources and dynamic capabilities of operations management and sustainable competitive advantages, this article reviews and systematizes the concepts used in the literature to determine the contribution of the operating system to the formation of competitive advantages of the company. The main characteristics of the dynamic capabilities are considered and on this basis the main challenges in the study of factors and causal relationships at the level of the operating system of the enterprise are presented, with an emphasis on the way of choosing independent and result variables, and the determination of causal relationships. Future research in the field of operations management that addresses the outlined challenges could contribute to a more comprehensive and complete study of dynamic capabilities in operations function. The research would be useful both for researchers in the field of operations management and for practitioners looking for sources and reasons for increasing the competitiveness of the companies in which they work.

Keywords: 
resource based theory, dynamic capabilities, competitive advantages, operations management.

Стефан Нанков Кампачев

ГА. ас. А-p

Катедра "Индустриален бизнес и могистика"

Стопански факултет

Икономически университет - Варна

Варна, Бъмгария

E-mail: stefan.kalpachev@ue-varna.bg

\section{Предизвикателства при детерминирането на приноса на операционната система за формирането на конкурентни предимства на предприятието}

Резюме:

Целта на тази статия е Аа очертае предизвикателствата при детерминирането на приноса на операционната система за формирането на конкурентни предимства на предприятието на база на приложението на РБТ. Поради растящия брой публикации правещи връзка межАу ресурсите и динамичните способности на операционния мениджмънт и устойчивите конкурентни предимства в настоящата статия е направен обзор и систематизиране на концепциите, използвани в митературата за определянето на приноса на операционната система към формирането на конкурентни предимства на фирмата. Разгледани са основните характеристики на динамичните способности и на тази основа са изведени основните предизвикателства при изследването на факторите и причинно-следствените връзки на равнище операционна система на предприятието, като е поставен акцент върху начина на избор на променливи и резултативни величини, и определянето на причинно-слеАствените връзки. Бъдещи изследвания в областта на операционния мениАжмънт, които се справят с очертаните предизвикателства биха могли да допринесат за по-комплексното и пъ нно изследване на динамичните способности в операционната функция. Изследването би било полезно както за изследователи в областта на операционния мениджмънт, така и за работещи в нея търсещи източници и причини за увеличаване на конкурентоспособността на фирмите в които работят.

Ключови думи:

ресурсно базирана теория, Аинамични способности, конкурентни предимства, операционен мениАжмънт.

\footnotetext{
Въведение

Популярен подход за изучаване на способностите в публикациите свързани с операционния мениджмънт на фирмата е да се оцени планираното или
} 
реализираното конкурентно оперативно представяне и приноса им за бизнес и организационните й цели. Въпреки че е важно да се илентифицират кои резултати на операционната система на предприятието помагат да се създаде конкурентно предимство, също толкова важно е Аа се разбере и кои са средствата за постигане на необходимата производителност на оперативно ниво. Именно в тази връзка широката приложимост на Ресурсно Базираната Теория (РБТ) за множество Аисциплини, водещо до нейното разширяване и Аопълване на теоретичните подходи, води до все по-широко използване на тази теория в изследванията на операционния мениджмънт. Фигура 1 показва процентното нарастване на публикациите в сферата на операционния мениджмънт, установено в изследване на Hitt et al. (Hitt et al., 2016).

РБТ постановява, че фирмите са в състояние да създават и подлържат конкурентни предимства чрез събирането и интегрирането на редки, ценни, неимитируеми и незаменими ресурси (Barney, 1991). Тази теория е важна за изследванията на операционния мениджмънт поради способността й Аа Аеконструира източниците на конкурентно предимство на фирмата, билейки както собствени за фирмата, така и външни (междуфирмени партньорства, вериги на доставки и т.н.). Освен това, вероятно поради разциките в нивата на анализ между стратегическо управцение (т.е. фирмата) и операции (т.е. функции и вериги на Аоставки), изследванията и публикациите в сферата на операционния мениджмънт(ОМ) продължават да разработват РБТ, като се фокусират върху процесите във и между фирмите, които могат колективно да създават или унищожават конкурентни предимства. Поради подходящото й приложение в тази област и нарастващата популярност сред изследователите на OM, целта на тази статия е да очертае предизвикателствата при детерминирането на приноса на операционната система за формирането на конкурентни предимства на предприятието на база на приложението на РБТ.

РБТ е широко използвана теоретична постановка за разбирането на източниците на конкурентно предимство от фирмите и как това предимство може да бъде подыържано с течение на времето (Barney, 1991; Nelson, 1991; Peteraf, 1993; Teece et al., 1997). Тази теория се фокусира върху вътрешната организация на фирмите и по този начин е Аопълнение към траАиционно отАаваната важност на стратегирането базирано на структурата на индустрията и 
стратегическото позициониране в рамките на тази структура като определящи фактори за конкурентно предимство (Henderson \& Cockburn, 1994; Porter, 1980).

По-специално, РБТ постановява, че фирмите могат да бъдат представени като съвкупности от ресурси, че тези ресурси са разнородно разпределени межау фирмите и, че разАиките в ресурсите се запазват с течение на времето (Amit \& Schoemaker, 1993). Въз основа на тези предположения авторите изследващи тези проблеми посочват, че когато фирмите разполагат с ценни, редки, неимитируеми и незаменими (т.е., така наречените ЦРНН атрибути), те могат да постигнат устойчиво конкурентно предимство чрез прилагане на нови стратегии за създаване на стойност, които не могат да бъдат месно Аублирани от конкуриращи се фирми (Barney, 1991; Conner \& Prahalad, 1996; Nelson, 1991; Peteraf, 1993), а когато тези ресурси и свързаните с тях системи от дейности се АопъАват, потенциацът им да създадат устойчиво конкурентно предимство се засилва (Collis \& Montgomery, 1998; Milgrom et al., 1991; Porter, 1996). Впоследствие се появяват публикации, които разширяват схващането за РБТ на Аинамични пазари (Теece et al., 1997), като се обосновава, че РБТ не обяснява адекватно как и защо някои фирми имат конкурентно предимство в ситуации на бърза и непредсказуема промяна. На тези пазари, където конкуренцията се променя, Аинамичните възможности, чрез които мениАжърите на фирми „интегрират, изгражАат и преконфигурират вътрешни и външни компетенции, за да се справят с бързо променящата се среда“" (Teece et al., 1997), стават източник на устойчиво конкурентно предимство, като се обръща специфично внимание, че манипулирането на ресурсите на знанието е особено критично на такива пазари (Grant, 1996).

Въпреки значимостта на РБТ, постановките й срещат съществени критики. Част от тях са, че е концептуално неясна и тавтологична, не изяснява механизмите, чрез които ресурсите действително допринасят за конкурентно предимство, а също така и за Аипса на Аостатьчно емпирични доказателства (Priem \& Butler, 2001; Williamson, 1999). Освен това се счита, че устойчивото конкурентно предимство е малко вероятно на динамични пазари (Teece et al., 1997).

\section{1. От ресурсно базирана теория към динамични способности}


Поради горепосочените критики в настоящата публикация ще се опитаме да очертаем предизвикателствата при летерминирането на приноса на операционната система за конкурентните предимства на предприятието в светлината на концепцията за динамичните способностие на предприятието. Морфологията на динамичните способности е сложна категория (Михайлова, 2013). По отношение на същността на Аинамичните възможности, как тези възможности се вАияят от динамиката на пазара и тяхното развитие във времето могат да бъдат посочени следните няколко характеристики на Аинамичните способности:

- Аинамичните способности се състоят от специфични стратегически и организационни процеси като разработване на продукти, обединяване и вземане на стратегически решения, които създават стойност за фирмите в рамките на динамични пазари чрез манипулиране на ресурсите в нови стратегии за създаване на стойност. Аинамичните способности не са нито неясни, нито тавтологично дефинирани абстракции (Eisenhardt \& Martin, 2000).

- Тези способности, които често са изследвани в рамките на обширни емпирични изследователски направления, показват общи черти при ефективни фирми или т.нар. общи „добри практики“. Следователно Аинамичните способности имат по-голяма еквивалентност, хомогенност и заменяемост между фирмите, отколкото предполага традиционното РБТ мислене.

- Ефективните проявления на динамичните способности варират, в зависимост от динамиката на пазара. Когато пазарите са умерено Аинамични, така че промяната да настьпва в обстоятелствата на стабилна индустриална структура, Аинамичните способности приличат на традиционната концепция за рутинните процедури (Cyert \& March, 1963; Nelson \& Winter, 1982). Тоест, те са сложни, подробни, аналитични процеси, които разчитат в голяма степен на съществуващите знания и последователното им изпълнение, за да произведат предвидими резултати. За разлика от това, на бързо променящите се пазари, където индустриалната структура се размива, Аинамичните способности придобиват разАичен характер. Те са прости, опитни, нестабилни процеси, 
които разчитат на бързо създадени нови знания и изпълнение от типа „проба-грешка“, за да дадат адаптивни, но непредсказуеми резултати.

- $\quad$ Аобре познатите механизми за учене и развитие ръководят еволюцията на Аинамичните способности и са в основата на зависимостта им от опита (Eisenhardt \& Martin, 2000).

- Функционалността на Аинамичните способности може да бъде Аублирана във фирмите, тяхната стойност за конкурентно предимство се крие в конфигурациите на ресурсите, които те създават, а не в самите способности;

- Аинамичните способности са необходими, но недостатьчни условия за конкурентно предимство. Счита се, че динамичните възможности могат Аа се използват за подобряване на съществуващите конфигурации на ресурсите в преследване на дългосрочно конкурентно предимство. Те обаче се използват много често и за изграждане на нови конфигурации на ресурси в преследване на временни предимства (Eisenhardt \& Martin, 2000).

Следователно, изучаването на операционните динамични способности на фирмата трябва да изследва тяхното съдържание и характеристики при разАични характеристики на пазарите, като същевременно изучава тяхното еволюционно развитие и преформулиране, описвайки както причините довели Ао това развитие, ресурсите и тяхната конфигурация, на които те стьпват като основа, така и резултатите, до които водят тези способности. Ако преАположим че има времева разлика между изграждането на нова ресурсна конфигурация и постигането на временно конкурентно предимство (проявлението на тази ресурсна конфигурация), то за изследването на динамичните способности е необходимо също така да се избере серия от „точни моменти“, в които трябва Аа бъдат взети резултативните величини.

\section{2. Предизвикателства при измерването на приноса на динамичните способности на операционната система на предприятието за формиране на конкурентни предимства}

\section{1. Операчионализиране на променливите}

ЕАно от важните предизвикателства за изследователите използващи РБТ и концепцията за Аинамичните способности е изолирането и операционализацията на променливите. КАючова концепция за РБТ и 
Аинамичните способности е неимитируемостта на изследваната способност, която воАи АО устойчиво конкурентно предимство и по-висока от средната възвръщаемост. Неосезаеми и трудни за наблюдение способности (процедури) са и трудни за имитиране по дефиниция.

При изолирането на променливите трябва да се отчете, че надеждното изолиране на способност е невъзможно без нейното пълно разбиране, но пълното разбиране на дадената способност Аава възможност на Аруги фирми Аа копират това, което прави фирмата уникална по отношение на нейните способности. Все пак трябва да се посочи, че описването на конкретна способност може Аа стане само при качествения анализ на фирми, които се представят добре (съответно зле) в даден сектор. Следователно от критична важност за правилното описване на динамична способност е това да става на база на задъцбочено качествено изследване, защото е необходимо условие изследването на способностите да става само когато изследващите способността напълно разбират ограниченията и потенциалните проблеми при прилагането

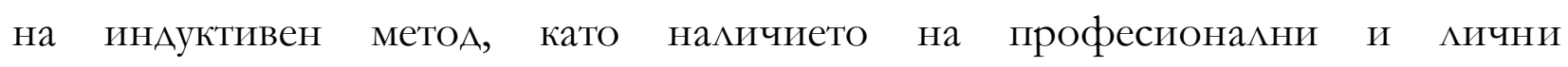
предубежления на изследователя , и също така да могат да засекат получаваната информация чрез оценката на различни респонденти и източници (Armstrong, 2007).

Аруго обстоятелство, което трябва да се има предвиА е, че за да се премахнат проблемите с наблюдаемостта на способностите трябва Аа се използва методика за извършване на сравнителни изследвания. Наблюдението на величини като ценност и неимитируемост е от значителна трудност, затова използването на Аъцбочинни интервюта с фокус -фирми и експерти трябва да смекчи проблемите свързани с измерването на проявцението на изследваната способност. Нужно е да се отчете, че се изследва специфично обстоятелство касаещо конкурентно превъзходство спрямо преки конкуренти. В тази връзка измерването на неимитируемостта трябва да се направи на базата на събирането на мнения на преки конкуренти и външни за Аадена фирма мичности. Възможно е мениджърите на дадена фирма да считат, че дадена процедура е ценна и трудна за имитиране, но същвременно преките конкуренти да не считат същото (Armstrong \& Shimizu, 2007).

Най-накрая, трябва Аа се постави изискване операционализирането на способностите да става чрез използването на обективни измерители. Поради 
трудностите, присъщи на измерването на динамичните способности, някои изследователи са намерили начини за строга операционализация на своите конструкции с наблюдаеми величини (Barney et al., 2004). Изследването на Армстронг от тип митературно ревю (Armstrong \& Shimizu, 2007) показва, че твърде много изследванията в областта Аинамичните способности използват еАинични индикатори за наличието на определена способност.

\section{2. Определяне на резултативната величина}

Основната цел на стратегическия мениджмънт на фирмата е да установи Аадено устойчиво конкурентно предимство и Аа определи как може систематично да го създава. Ако фирмите могат да постигнат над считаните за нормални резултати за продъцжителен периол от време, то може да се счете, че те са постигнали устойчиво конкурентно предимство. (Amit \& Schoemaker, 1993; Barney, 1991). Тази концепция може и да е важна за изследването на Аинамичните способности на фирмата, но по-голямата част от изследванията в областта на динамичните способности я пренебрегват. Армстронг (Armstrong \& Shimizu, 2007) посочва,че от емпирична гледна точка в това отношение може да се посочи известно заструднение, понеже не съществува конкретна единно приета мярка за „устойчивост“ по отношение на продъцжтелността или степента на конкурентоспособност. Също така тази продъцжителност на конкурентното предимство може да бъде различна за различните сектори на производството. Аопълнително затруднение оказва обстоятелството, че способности, които са цесни за имитиране също биха могли да допринесат за наличието на временно конкурентно предимство и да благоприятстват крайните резултати на фирмата (Barney, 1991).

Отчита се, че не малка част от изследванията използват като резултативна величина показателят „възвращаемост на активите“ (return on assets - ROA) (Armstrong \& Shimizu, 2007; Barney et al., 2004). Барни (Barney et al., 2004) от своя страна Аоказва, че тьй като способностите преАстав яват специфични процеси, то правилната резултативна величина е ефективността на изследвания бизнес процес. За това има няколко причини - ако фирмата разчита на няколко процеса да генерират конкурентни предимства, то единият от процесите може Аа генерира конкурентно предимство, но другият да генерира недостатьк и като крайно проявление финансов показател не би показал доколко ефективно 
Аадена способност генерира конкурентно предимство за фирмата. Аруг довод за използването на ефективност на бизнес процеса като резултативна величина е, че финансовите показатели са зависими от много фактори, част от които е и поведението на заинтересованите мица, които могат по разАични причини Аа присвоят генерирания финансов резултат от дадено конкурентно предимство.

Следователно, за да се детерминира доколко конкурентното предимство е устойчиво е нужно е да се използва т.нар. Аонгитюдно изследване, защото само чрез него могат да се изследват динамичните взаимоотношения във времето и да се проследи как условията, при които се развиват или придобиват способности в един период, вАияят върху стратегическите предимства на фирмите в следващите периоди.

\section{3. Определане на „конструкта“" на изследването}

Bсе още в митературата посветена на динамичните способности няма единно мнение по отношение на структурата, съдържанието, нивата на анализ и моделите за оценка на динамичните способности (Михайлова, 2013; Михайлова, 2020). Именно поради това и в сферата на операционния мениджмънт към момента няма публикации опитващи се изчерпателно да опишат съвкупността от Аинамични способности на операционния мениАжмънт. ЕАна голяма част от изследванията в операционния мениджмънт изследват една детерминирана способност и изследват връзката й с определена резултативна величина (Hitt et al., 2016). В съответствие с разнопосочността на мненията на авторите по отношение на равнищата на Аинамичните способности и тяхното проявление при управлението на операциите на фирмата - т.е. дали те могат да бъдат Аекомпозирани на Аинамични способности от няколко равнища, на рутинни процеАури и „висшестоящи“ Аинамични способности и на рутинни процедури, чието инкорпориране в Аинамична способност е отвъд обхвата на операционния мениджмънт можем да опишем няколко подхода:

- Изследване на приноса на конкретни „добри практики“ за постигането на конкретни индикатори на изпълнението свързани с операционните приоритети на предприятието (едностепенен модел на изследване). Този подход има предимството да изследва дадена „практика“ на базата на детайлизирано изучаване на характеристиките й, на базата на което оценката на нейното „ниво“ на прихагане да бъде извършено на базата на 
многобройни качествени променливи, които Аа бъдат обвързани със значението на определен резултативен количествен показател. Примери, които се дават в митературата за извършени подобни изследвания върху подобни „рутини“ са практики като многофункционално обучение на работници, производствени системи от типа „точно навреме“, използване на статистически контрол на процесите, развиването на собствено оборудване и т.н. (Ketokivi \& Schroeder, 2004).

- Изследване на приноса на дефинирана динамична способност за формирането на конкурентно предимство на базата на Авустепенна структура (Авустепенен модел). При този тип изследвания способността е дефинирана като силата или високата степен на овладяване на съвкупност от взаимосвързани „пакети“ от рутинни процедури за изпълнение на конкретни задачи (Peng et al., 2008). Основен въпрос, който поражда такъв подход е доколко Ааден „пакет“ от рутинни процедури се съотнася само и единствено до съществуването на динамичната способност, чийто принос се измерва. Примери, които могат да се дадат са изследванията на способностите за непрекъснато усъвършенстване и иновиране (Peng et al., 2008).

- Комплексно изследване на динамичните способности, обвързани на базата на изследвани вече в митературата и известни операционни приоритети, обвързани в система и описващи възможно най-добре влиянието и зависимостите между отделните „способности“. Аоводите за това дефиниране на динамичните способности са, че операционните приоритети са предвидени, „способности“. Те са способности, които операционния мениджмънт на фирмата иска да има в бъдеще, или способности, върху които трябва да се постави акцент в бъдеще (Größler \& Grübner, 2006). Предимството на този подход, е че изследването на възможно най-пълния набор от „планирани“ способности Аава възможност да се проведе изследване за характера на взаимодействието и взаимното влияние межАу тези способности, при което ако детерминирането на приоритетите се осъществи на базата на предварително Аълбочинно проучване и се изследват сходни по характер производства е възможно Аа се избегне или поне да се намали възможността да останат неизследвани променливи и фактори, както и да се дале възможно най-пълно изследване 
на резултативната величина. Също така подобен род изследвания са най подходящи и за измерване на проявлението на факторите в няколко времеви интервала.

От казаното дотук следва да се заключи, че при определянето на приноса на Аинамичните способности на операционната система за създаването на устойчиви конкурентни предимства трябва да се използват внимателно подбрани променливи, като една способност или „добра практика“ трябва да бъде описвана чрез няколко променливи с цел обективизиране на резултата. При резултативните величини трябва да се използват показатели пряко свързани с ефективността на изследваните процеси дефинирани като Аинамични способности, същевременно при определянето на конструкта на изследването трябва да се отчитат контекстуанните характеристики от гледна точка на динамика на изследвания пазар, изолируемост на практиките, сектор на изследваните фирми, възможност да се очертаят ясно причинно-следствени връзки межАу рутинни процедури и дефинирани способности. Изследването на конкурентните предимства свързани с операционната функция трябва да става на базата на продъцжителен период на изследване.

\section{3. Аискусия}

В настоящата публикация очертахме предизвикателствата свързани основно с избора на променливи, избора на подходяща резултатативна величина и дизайна на изследването. Редно е да се отчете, че при описанието на неосезаема променлива упомената като някаква Аинамична способност поголямата част от изследванията използват субективни оценки на работещи в Ааден сектор на ниво оперативен директор, началник цех и т.н. Следва да поставим пол въпрос Аали отговорите на респондентите са отражение на истинското състояние на избраната характеристика(Ketokivi \& Schroeder, 2004), особено ако в даден сектор няма възприети определени конкретни стандарти за представяне на операционната система.

Второ ограничение на изследванията е избора на конкретни фирми и отрасли. Изчисляването на показате к като „производителност на труда“ е силно зависимо от обстоятелства като използване на подизпълнители и доколко целият процес по производство на комплектуващи и полуфабрикати(детайли) се извършва в рамките на дадена фирма. От Аруга страна описването на 
определена динамична способност вероятно е силно зависимо от сектора и типа индустрия. За да може да се правят значими заключения и сравнения е редно участващите в изследването фирми/предприятия да са поне със силно уеднаквени характеристики като тип на производството, характер на търсенето, характер на използваните материали, и обем на произвежданите продукти.

\section{Закиючение}

В статията са изведени и анализирани основните предизвикателства за оценката на приноса на Аинамичните способности на операционния мениджмънт към формирането на устойчиви конкурентни предимства на фирмата. Въз основа на извършените анализи се достигна до следните по-важни изводи и закАючения:

- $\quad$ Аинамичните способности са по-подходящата концепция за определяне на влиянието на операционния мениджмънт върху конкурентните предимства на фимата спрямо статичната концепция за тьрсенето на „ресурси“.

- $\quad$ За извършването на коректно изследване детерминирането на изходните променливи трябва да става на базата на залълбочено разбиране на характеристиките и прояв ението на изследваните способности, като за целта трябва да се използва качествен анализ, фокусни проучвания и обективни измерители.

- 3 а резултативна величина трябва да се избират пряко обвързани с резултатността на изследваните процеси величини на микро ниво, но не и финансови показатели, които се влияят от цялостната дейност на фирмата. Устойчивостта на конкурентното предимство трябва Аа се извършва на базата на Аонгитюдни изследвания.

- Коректното определяне на изследвания „конструкт“ е от критично значение за детерминирането на връзките и посоките на влияние на изследваните способности, както за разкриването на характера на тяхното въздействие върху конкурентните предимства на фирмата, така и за разкриването на вАиянието помежАу им. 


\section{Списък с изпомзвана митература:}

Михайлова, М. (2020). Аискусионни аспекти в моделите за операционализиране на динамичните способности. Аиалог, 1, 16-32. Свищов: АкаА. изА. Ценов.

Михайлова, М. (2013). Морфология на икономическата категория динамични способности. Известия Сn. Икон. унив., 1, 99-111. Варна: Наука и икономика.

Amit, R. \& Schoemaker, P.J.H. (1993). Strategic assets and organizational rent. Strategic Management Journal, 14, 33-46. (на английски)

Armstrong, C.E. \& Shimizu, K. (2007). A review of approaches to empirical research on the resource-based view of the firm. J. Manag, 33 (6), 959-986. (на английски)

Barney, J.B. (1991). Firm resources and sustained competitive advantage. J. Manag, 17, 99-120. (на английски)

Barney, J., Ray, G., \& Muhanna, W. (2004). Capabilities, Business Processes, and Competitive Advantage: Choosing the Dependent Variable in Empirical Tests of the Resource-Based View. Strategic Management Journal, 25 (1), 23-37. (на английски)

Conner, K.R. \& Prahalad, C.K. (1996). A resource-based theory of the firm: knowledge versus opportunism. Organization Science, 7(5), 477-501. (на английски)

Collis, D.J. \& Montgomery, C.A. (1998). Creating corporate advantage. Harvard Business Review, 76(3), 70-83. (на английски)

Cyert, R.M. \& March, J.G. (1963). A Behavioral Theory of the Firm. Prentice-Hall: Englewood Cliffs, NJ. (на английски)

Eisenhardt, K.M. \& Martin, J.A. (2000). Dynamic Capabilities: What Are They? Strategic Management Joumal, 21(10/11), 1105-1121. (на английски)

Grant, RM. (1996). Toward a knowledge-based theory of the firm. Strategic Management Journal, Summer Special Issue 17, 109-122. (на английски)

Größler, A. \& Grübner, A. (2006). An empirical model of the relationships between manufacturing capabilities. International Journal of Operations \& Production Management, 26, 458-485. (на английски)

Henderson, R. \& Cockburn, I. (1994). Measuring competence? Exploring firm effects in pharmaceutical research. Strategic Management Journal, 15, 63-84. (на английски)

Hitt, M.A., Xu, K., \& Carnes, C.M. (2016). Resource based theory in operations management research. J. Op. Manag, 41, 77-94. (на английски) 
Ketokivi, M. \& Schroeder, R. (2004). Manufacturing practices, strategic fit and performance - A routine-based view. International Journal of Operations \& Production Management, 24, 171-191. (на английски)

Milgrom, P, Qian, Y, \& Roberts, J. (1991). Complementarities,momentum, and the evolution of modern manufacturing. American Economic Review, 81(2), 84-88. (на английски)

Nelson, R.R. (1991). Why do firms differ, and how does it matter? Strategic Management Journal, 12, 61-74. (на английски)

Nelson, R. \& Winter, S. (1982). An Evolutionary Theory of Economic Change. Belknap Press: Cambridge, MA. (на английски)

Peng, D.X., Schroeder, R.G., \& Shah, R. (2008). Linking routines to operations capabilities: a new perspective. J. Oper. Manag, 26, 730-748. (на английски)

Peteraf, M.A. (1993). The cornerstones of competitive advantage: A resource-based view. Strategic Management Journal, 14, 179-191. (на английски)

Porter, M.E. (1980). Competitive strategy. New York: Free Press. (на английски)

Porter, M.E. (1996). What is strategy? Harvard Business Review, 74(6), 61-78. (на английски)

Priem, R.L. \& Butler, J.E. (2001). Is the resource-based 'view' a useful perspective for strategic management research? Academy of Management Review, 26(1), 22-40. (на английски)

Teece, D.J., Pisano, G., \& Shuen, A. (1997). Dynamic capabilities and strategic management. Strategic Management Journal, 18, 509-533. (на английски)

Williamson, O.E. (1999). Strategy research: governance and competence perspectives. Strategic Management Journal, 20(12), 1087-1108. (на английски) 


\section{Приможение}

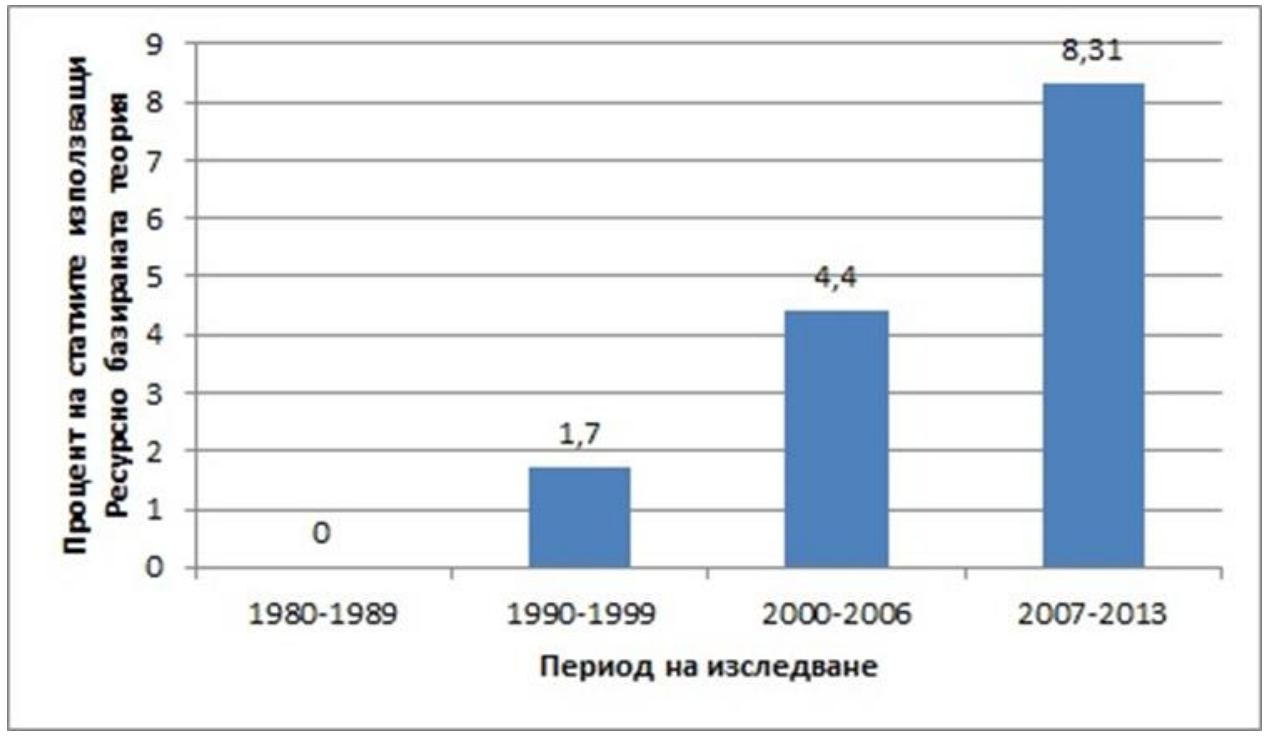

Фигура 1. Ръст в използването на ресурсно базираната теория в изследванията на операционния мениджмънт (Hitt et al., 2016, 77-94) 